\title{
EDUCAÇÃO PROFISSIONAL: A NORMALIZAÇÃO BIOPOLÍTICA DA SUBJETIVIDADE DO TRABALHADOR
}

\author{
Samuel Brasileiro Filho ${ }^{1}$
}

\section{Resumo:}

O presente artigo realiza uma investigação teórica sobre as condições de existência da subjetividade produtiva e suas implicações com a relação entre o trabalho e a educação, tendo como contexto histórico da transição da sociedade industrial para a sociedade pósindustrial, adotando-se um referencial teórico fundamentado no pensamento de Karl Marx e Michel Foucault. Com base na filosofia de Marx a existência da subjetividade produtiva está diretamente relacionada com a forma de produção, porém sua abordagem sobre a subjetividade, enquanto consciência do trabalhador, não é limitada pelo determinismo economicista, mas ampliada para uma ontologia do ser social. A transição para sociedade pós-industrial promove a emergência de crescente hegemonia qualitativa do trabalho imaterial, os quais associados ao processo de reestruturação produtiva conformam novas condições de existência subjetiva, uma existência biopolítica da subjetividade produtiva, a qual é analisada segundo o conceito de Biopolítica de Foucault. O texto é finalizado com uma sucinta análise no modelo das competências como um exemplar dispositivo de normalização subjetiva da sociedade pós-industrial.

Palavras Chave: Educação Profissional, Subjetividade, Biopolítica.

\begin{abstract}
:
This article makes a theorical investigation about the conditions of existence of productive subjectivity and its implications to relation between work and education, considering the historical context of transition from industrial to post-industrial society, adopting a theorical approach based in Karl Marx and Michel Foucault. According Marx's thoughts the existence of a productive subjectivity is direct connected to the production form, although his approach about subjectivity as worker's conscience, it isn't limited by the determinism of economical system, but has an enlarged vision as ontology of the social self. With the transition to the post-industrial society emerges an increasing qualitative hegemony of non material work, which is related to revolutionary changes in production system that turned possibly news conditions of subjectivity existence, as a biopolitical subjectivity that is analyzed according Foucault's concept of biopolitic. The text is concluded with a short analyses about the competence model as an exemplar dispositive of subjectivity normalization in post-industrial context.
\end{abstract}

Key Words: Professional Education, Subjectivity, Biopolitc.

\footnotetext{
${ }^{1}$ Professor do Instituto Federal de Ciência e Tecnologia do Ceará (IFCE). Doutorando em Educação pela Universidade Federal do Ceará (UFC), vinculado a linha de pesquisa Filosofia e Sociologia da Educação. Membro do Núcleo de Pesquisa NUPEP do IFCE e Conselheiro do Conselho Estadual de Educação. E-mail: samuel@ifce.edu.br
} 


\section{Introdução - A Subjetividade Produtiva}

Uma abordagem teórica do conceito de subjetividade, mesmo delimitada a uma tipologia específica de subjetividade produtiva, não é uma temática simples e seu tratamento conceitual apresenta certa complexidade em função da natureza polissêmica e interdisciplinar de tal conceito, que se constitui numa das principais questões da tradição filosófica ao investigar sobre a verdade do ser do homem. Tal abordagem, conforme se propõe, neste breve artigo, aponta para o enfrentamento da seguinte questão: como funciona ou em que consiste o modo de ser do homem que vive do trabalho e como esta subjetivação produtiva tem sido conformada ao longo da história?

A questão da Subjetividade é tema central na tradição filosófica e a sua abordagem apresenta uma dificuldade adicional que é relacionada com a diversidade e amplitude dos referenciais teóricos adotados em seu tratamento ao longo da evolução histórica do pensamento filosófico. Considerando-se a delimitação da temática proposta, onde se pretende realizar uma investigação introdutória da relação entre a educação profissional e os processos de produção da subjetividade do trabalhador, no contexto de transição da sociedade industrial para a pós-industrial, torna imperativo analisar como a relação entre Trabalho e Educação tem sido moldada pelas conformações subjetivas resultantes do embate entre as concepções de organização dos sistemas produtivos e dos sistemas educativos.

Segundo Gondin e Rodrigues (2009) a investigação da subjetividade é a temática central da ontologia, mas a ontologia, através da história do pensamento, não teve um significado linear; sofreu diversas mudanças quanto à forma de definir o seu objeto: o ser. Assim sendo, a cada etapa histórica podem-se constatar cortes e rupturas isto significando que o conceito de ser não é unidimensional, por causa disto é fundamental conhecer as mais variadas etapas históricas do saber ontológico com suas respectivas definições do ser. Tal tratamento histórico da subjetividade foge do escopo do presente trabalho, mas ressalta-se a sua importância para a investigação dos processos de formação das condições de existência da subjetividade.

$\mathrm{Na}$ investigação da temática proposta, delimitada na abordagem dos processos de produção da subjetividade do trabalhador e suas relações com a educação 
profissional entre a transição da sociedade industrial e a pós-industrial, também será delimitada pela adoção de categorias analíticas da relação trabalho e educação, fundamentadas nos pensamentos Karl Marx e Michel Foucault, em função da referencial contribuição que estes autores deram para a investigação da ontologia do ser que vive do trabalho. Neste sentido, pretende-se contribuir modestamente com as discussões e debates desta atual e relevante temática do I Colóquio de Filosofia da Educação: Subjetividade e Educação, realizado pela Coordenação do Programa de Pós-Graduação em Educação da Faculdade de Educação da Universidade Federal do Ceará, no período de 13 a 15 de outubro de 2010.

\section{As Condições de Existência da Subjetividade Produtiva em Marx e} Foucault.

A conformação da subjetividade é um processo ontológico, portanto multidimensional, social e historicamente condicionado. Segundo Saviane (2007) a análise dos fundamentos ontológicos e históricos do trabalho e da educação aponta para uma análise integrada destas categorias, pois o ser do homem, e, portanto o ser do trabalho, é tanto histórico quanto ontológico. O mesmo vínculo ontológico-histórico se dá entre a relação trabalho-educação e os processos de formação da subjetividade produtiva com a evolução do conhecimento humano, materializada nas tecnologias produtivas, nos modelos gerenciais do trabalho e nas relações de poder que têm implicação na subjetivação e objetivação dos sujeitos do trabalho, as quais são ao mesmo tempo resultantes de sociabilidades produtivas e de práticas educativas.

\subsection{Elementos da Subjetividade Produtiva no Pensamento de Karl Max e suas Implicações para Investigação da Sociedade Industrial}

Retomando-se a pergunta de partida do presente trabalho, assim formulada: como funciona ou em que consiste o modo de ser do homem que vive do trabalho e como esta subjetivação produtiva tem sido conformada ao longo da história? Para Saviani(2007) o homem não nasce homem, ele forma-se homem, ele precisa aprender a ser homem, precisa aprender a produzir a própria existência. Assim a origem do ser homem, coincide com a origem do trabalho e da educação, enquanto condições essência de existência da subjetividade.

\begin{tabular}{|l|l|l|l|l|} 
Revista Dialectus & Ano 1 & n. 1 & Julho-Dezembro 2012 & p. 240-256 \\
\hline
\end{tabular}


Na Obra de Marx e Engels (1974) a essência do ser homem e o diferencial da existência animal é que este necessita produzir seus meios de vida, produzindo indiretamente a sua própria vida material. Tal afirmação estabelece a primazia da categoria trabalho como fundante da subjetividade humana. Assim a formação do ser que trabalha é um feito humano, numa espécie de recursividade subjetiva, que se desenvolve, se aprofunda e evolui ao longo do tempo em um processo ontológico e histórico cada vez mais complexo.

$\mathrm{Na}$ fundamentação do pensamento marxista a formação da subjetividade produtiva na sociedade capitalista é diretamente relacionada com os modos de reprodução das relações de produção, o que, de certa maneira, sugere um caráter decisivo da educação na reprodução das relações de produção capitalista, cuja separação entre educar e trabalhar, entre educar para pensar e educar para trabalhar, consolida um processo de produção de subjetividade que caracteriza pela aculturação da classe que vive do trabalho e uma crescente perda de significação do trabalho.

Segundo Correa e Teixeira (2010) o pensamento de Marx sobre a subjetividade tem sido alvo de críticas com ênfase para sua fundamentação da noção de consciência a partir de conceitos de infra-estrutura, superestrutura, base e ideologia, que conduzem a uma interpretação mecanicista da relação entre subjetividade e o contexto sócioeconômico. Tais críticas tais críticas são questionadas, segundo Berino (1994), com base na tese de que Marx desenvolveu em sua teoria uma ontologia do ser social ampliando sua análise da questão da subjetividade para além dos conceitos de base e de ideologia, por meio de uma complexa arquitetura categorial. Para o citado pesquisador a divisão social do trabalho resultou na expropriação dos trabalhadores dos produtos de seu trabalho, o que é tratado por Marx fundamentalmente por meio da ótica da inversão, por meio dos conceitos de alienação, ideologia e fetiche da mercadoria.

Sob esta visão, a subjetividade produtiva se constituiria numa dinâmica em que, simultaneamente atividade e passividade, se articulam na conformação do ser do trabalho. Corrêa e Teixeira (2010) afirmam que na concepção marxista a dinâmica de forças que se estabelecem na divisão de classes no sistema capitalista, apenas a classe trabalhadora tem condições de promover mudanças significativas nas relações sociais de forma a superar o sistema de produção capitalista e os processos de subjetivação alienantes. Tal afirmação embute uma potencialidade subjetiva revolucionária na classe que vive do trabalho. 
Sob o esteio da modernidade, surge a ideologia liberal a qual, segundo Sanson (2009), possibilita liberar a iniciativa privada, o gosto pelo risco e pelo esforço, o sentido de competição, os quais assentados nos preceitos da modernidade possibilitam a conformação do sujeito moderno, na perspectiva de um indivíduo capaz de fazer valer o seu julgamento frente aos fatos da realidade objetiva, ganhando relevo, como afirma Tourrine (1999), de um status de sujeito como a vontade de um indivíduo de agir e de ser reconhecido como ator.

De acordo com Sanson (2009) com a revolução industrial e seu novo modo de produção capitalista, o sujeito do trabalho perde o controle sobre o seu trabalho, o qual passa ser fragmentado e desvinculado de um saber centrado no trabalhador, fazendo com que a força produtiva que este desenvolve como sua própria subjetivação passe a ser força produtiva de reprodução do capital, representando a constituição de uma nova subjetivação produtiva assujeitada.

Segundo Marx e Engels (1974) no modo de produção capitalista que se instaura na sociedade industrial a produção de um objeto, de uma mercadoria, é estranha ao seu produtor, introduzindo a análise categorial do trabalho alienado e da fetchização da mercadoria. Sob tal abordagem, observa Sanson (2009) que há uma inversão da relação entre o sujeito do trabalho e seu objeto. Há uma objetivação do sujeito do trabalho e uma subjetivação do objeto, onde o sujeito se torna objeto e o objeto ganha vida. No pensamento marxista a subjetivação produtiva, com advento da sociedade industrial, se manifesta como uma subjetividade coisificada.

Sanson (2009), abordando a subjetivação em Marx, afirma que, apesar da alienação, do fetichismo, do estranhamento, sujeição, até mesmo corporal, que se processa no trabalho alienado, essas mesmas relações de produção produzem reações subjetivas à exploração, numa espécie de subjetividade de resistência. Tal subjetividade revolucionária emerge das relações de contradição entre o capital e o trabalho e da tomada de consciência da classe trabalhadora como classe explorada geradora da mais- valia apropriada pelo capital.

Com tal visão pode-se afirmar que a organização do trabalho na sociedade industrial, modelou a subjetividade produtiva, gerando a classe operária. A modernidade, a ideologia liberal e modo de produção industrial, fortalecido pela incorporação das máquinas e das técnicas, conformaram o homo faber como um sujeito laboral que só sabe viver de seu trabalho, e que está programado para ser feliz. 
A continuidade da complexificação do trabalho e de constituição da classe operária, aliado ao desenvolvimento de uma nova inteligibilidade produtiva inspirada na inteligência industrial de Ford, na inteligência gerencial de Taylor e Fayol e na inteligência econômica de Keynes, dentre outras significantes contribuições, estabeleceuse um novo momento histórico da sociedade industrial, o qual foi denominado de segunda revolução industrial, marcado pelo surgimento da grande indústria e do processo de produção em massa, denominado de modelo de produção Taylorista - Fordista, ou simplesmente fordismo.

Para Sanson (2009) o modelo da organização do trabalho que servia de base à economia industrial fordista tornou-se insuficiente, ou seja, a redução do trabalho complexo ao trabalho simples, a separação da execução manual da concepção intelectual, a industrialização e especialização da atividade laboral, não mais são capazes de responderem aos novos padrões competitivos e às exigências no novo paradigma produtivo implantado pela reestruturação produtiva, pela incorporação das tecnologias de comunicação e informação e pela emergência da hegemonia qualitativa do trabalho imaterial. Tal mudança aponta a transição da sociedade industrial para a sociedade pósindustrial, gerando novas condições de existência da subjetividade produtiva.

Tais condicionantes da formação da subjetividade produtiva, na era pós- industrial com a emergência da hegemonia qualitativa do trabalho imaterial enquanto elemento inovador de valorização do capital impõe restrições à aplicação das categorias marxistas para a análise das condições de objetivação e subjetivação dos trabalhadores, apontando para a necessidade de exploração de uma nova arquitetura categorial complementar à análise marxista que seja capaz de dar conta deste novo contexto social e histórico das condições de existência da subjetividade produtiva.

\subsection{As Bases da Investigação da Subjetividade Produtiva no Pensamento de Michel Foucault.}

Segundo Corrêa e Teixeira (2010) na obra de Foucault toda experiência humana vivida no interior da sociedade capitalista seria perpassada por relações de poder. Daí porque o exercício de poder não seria privilégio apenas dos grupos dominantes e nem das instituições, existindo uma reversibilidade e reciprocidade entre relações de poder e as lutas históricas e sociais, de modo que não haveria poder sem a existência de 
mecanismos de resistência e liberdade. É neste contexto que se estabelece a ontologia do sujeito, como principal tema investigativo de Foucault, na concepção de que é na imanência da história, na dobra da realidade, que o sujeito foucaultiano se constitui como produto e resistência às técnicas de dominação.

No início de organização da sociedade capitalista, entre o século XVII e XVIII, como afirma Foucault (2000), emergiram as técnicas de poder que foram essencialmente centradas no corpo, no corpo individual, tendo sido assim descritas por Foucault:

\begin{abstract}
Eram todos aqueles procedimentos pelos quais se assegurava a distribuição espacial dos corpos individuais (sua separação, seu alinhamento, sua colocação em série e em vigilância) e a organização, em torno destes corpos individuais, de todo um campo de visibilidade. Eram também as técnicas, pelas quais se incumbiam desses corpos, tentavam aumentar-lhes a força útil através do exercício, do treinamento, etc. Eram igualmente técnicas de racionalização e de economia estrita de um poder que devia se exercer, da maneira menos onerosa possível, mediante todo um sistema de vigilância, de hierarquias, de inspeções, de escriturações, de relatórios: toda essa tecnologia, que podemos chamar de tecnologia disciplinar do trabalho. (FOUCAULT, 2000, p.288)
\end{abstract}

Pode-se afirmar que o trabalho e a educação sofreram forte influência destas tecnologias disciplinares, as quais possibilitaram a entrada do poder disciplinar no jogo político e o nascimento do Estado moderno. Tanto as esferas do trabalho, quanto a da educação, passaram ao status de espaços de direitos, porém regulados numa estrutura disciplinar, num Estado que é ao mesmo tempo, individualizante e totalitário. Nesta ambiência de tecnologia de vigilância, a educação ganha uma posição de regulação social, a qual associada às tecnologias disciplinares do trabalho trata de forjar corpos dóceis e as condições básicas para o estabelecimento de uma divisão social do trabalho.

Segundo Foucault (2000), durante a segunda metade do século XVIII, vai aparecer algo novo, que é outra tecnologia, uma nova tecnologia de poder que não exclui a tecnologia disciplinar, mas que a integra e modifica que não mais se aplica meramente ao corpo, mas à vida, ao homem-corpo, ao homem-espécie. Foucault denomina esta nova técnica de poder de biopolítica da espécie humana, fundamentada na articulação entre as tecnologias disciplinares do corpo com as novas tecnologias de controle da população. Para Foucault (2000), o nascimento da biopolítica trata-se de

Um conjunto de processos como a proporção dos nascimentos e de óbitos, a taxa de reprodução, a fecundidade de uma população, etc. São esses processos de natalidade, de mortalidade, de longevidade que, justamente na segunda metade do século XVIII, juntamente com uma porção de problemas econômicos e políticos, constituíram os primeiros objetos de saber e os primeiros alvos de controle dessa biopolítica. (FOUCAULT, 2000, p.290) 
Para Foucault (2000) a biopolítica surge como tecnologia de poder que tem como foco um novo personagem no jogo político: a população, tratada como um problema político e científico. As tecnologias de controle da população, com seus cálculos estatísticos e seus mecanismos de medição e de previdência em torno desse aleatório de populações vivas, vai atuar diferentemente das tecnologias disciplinares do corpo mediante mecanismos globais, de ações destinadas à obtenção de estados globais de equilíbrio, de regularidade, em resumo, de levar em conta a vida, os processos biológicos do homem-espécie e de assegurar sobre eles não uma disciplina, mas uma regulação.

O desenvolvimento da sociedade capitalista, acompanhada da explosão populacional e da industrialização - pois o poder soberano não conseguia mais dar conta desta problemática complexa - a qual promoveu profundas mudanças em várias esferas da vida humana. Na esfera da educação, assim como em outras esferas da vigilância e do treinamento, a biopolítica promoveu a sua primeira acomodação, a qual orientou, já no século XVII, a organização da escola como espaço de socialização e aprendizagem.

A educação além de manter funções de regulação social, assume, no contexto do liberalismo, as funções de formação do cidadão produtivo, capaz de operar os processos produtivos cada vez mais incorporadores de maquinarias e novas tecnologias produtivas. Disso resulta segundo Veiga-Neto (2007, p.69), a ampliação do papel conferido à escola como instituição de regulação social, de modo que o deslocamento neoliberal a que hoje se assiste - da educação como direito para a educação como mercadoria - terá implicações que vão além do que as análises marxistas costumam apontar.

A educação, sob a governamentalidade biopolítica, assume papel fundamental no desenvolvimento das forças produtivas da sociedade capitalista, na medida em que se tornam mais complexos os processos de produção, pela crescente incorporação de inovações tecnológicas e modernização das técnicas de gestão do trabalho, a ponto de fundamentar uma das bases da governamentalidade neoliberal na forma da teoria do capital humano.

A esfera do trabalho também sofre forte influência da nova tecnologia de poder que emerge com a biopolítica. $\mathrm{O}$ trabalho considerado na sua historicidade e na sua ontologia social se configura e adquire forma a partir das práticas de poder e saber, que formulam os efeitos de verdade que o constituem. Neste aspecto, o trabalho, sob a influência das tecnologias de controle biopolítico, sofre novas formas de controle no 
processo produtivo e na subjetivação e objetivação do trabalhador. A análise sociológica da categoria trabalho, no contexto da biopolítica, deve, portanto, operar deslocamentos produtivos para a emergência de um trabalhador coletivo e novas formas de controle, que superem os modelos disciplinares de treinamento e vigilância.

Segundo Lima (2010, p.99), na chamada primeira revolução industrial o corpo do trabalhador era tratado como corpo-máquina e as máquinas introduzidas no sistema produtivo substituíam a força motriz humana ou animal, enquanto principal fator de realização de trabalho. Neste ambiente, onde as práticas de saber e poder estavam vinculadas a um modelo de trabalho orientado para a invidualização, para a especialização produtiva numa linha de produção em massa e padronizada, as tecnologias disciplinares constituíam o modelo de regulação do processo produtivo. A expansão da industrialização foi acompanhada de uma expansão da população operária, levando a necessidade de agregação da nova tecnologia política de controle da classe trabalhadora. É neste contexto que o modelo de produção taylorista-fordista se instala.

Lima (2010) aponta uma nova mudança na esfera do trabalho promovida pela denominada segunda revolução industrial, onde o desenvolvimento científico e tecnológico apropriado pelos sistemas produtivos possibilita a criação de máquinas capazes de substituir não apenas a força-motriz humana, mas de substituir os processos informativos de decisão e controle exercidos pelos trabalhadores. Tal substituição denuncia uma grande mudança na esfera do trabalho, a passagem da atuação de mecanismos disciplinares do corpo-máquina sobre trabalhador a um novo corpo impactado pela informação que atua sobre a força de trabalho.

Lima (2010) afirma que a passagem do corpo-máquina ao corpo-informação Inscreve-se no âmbito de duas grandes transformações. Uma primeira, que diz
respeito às mudanças das sociedades industriais para sociedades pós-
industriais ou informacionais. Uma segunda, que está na base material dessa
mudança de modelo de sociedade - a mudança de paradigma tecnológico: a
transição do paradigma mecânico ao informacional. (LIMA, 2010, p. 98)

Uma questão a ser considerada, na análise da relação entre Trabalho e Educação na emergência da biopolítica, é o deslocamento do trabalho como principio educativo para o trabalho como problema biopolítico-educativo. A questão central então passa a ser em conhecer como a relação entre trabalho e educação entra nas relações sócio- históricas, enquanto práticas de saber e poder das quais esta relação é investida?

$\mathrm{Na}$ transição da sociedade Industrial para a sociedade pós-industrial a lógica de acumulação capitalista mantem a mesma dinâmica de acumulação e reprodução do 
capital orientada pela introdução de inovação tecnológica e de organização do trabalho no processo produtivo, porem diferencia-se no modo de produção da subjetividade produtiva. Uma diferença essencial é que na primeira a acumulação é intensiva em capital e na segunda a acumulação se dá em capital e conhecimento, com primazia para o conhecimento, o qual assume o papel de principal fator de geração de valor.

De acordo com Sanson (2009) a forma de trabalho associada à sociedade pósindustrial, pós-fordista, conforma-se com uma passagem de uma lógica da reprodução para uma lógica da inovação, de um regime de repetição a um regime de inovação. Neste novo contexto histórico de transição da sociedade industrial para a pós-industrial o sujeito do trabalho, nesse caso, assume o papel de agente do trabalho imaterial, pois seu saber e seu conhecimento - recursos imateriais - assumem papel relevante de enriquecimento do trabalho e de geração de valor.

Os processos de formação da subjetividade produtiva no contexto da sociedade pós-industrial, com a crescente hegemonia qualitativa do trabalho imaterial, revaloriza a subjetividade dos trabalhadores, por meio do reconhecimento de que o conhecimento, a comunicação e a cooperação são as categorias fundamentais da nova organização do trabalho, as quais estão vinculadas ao estabelecimento de relações intersubjetivas entre sujeitos singulares desenvolvidas mediante os processos sociais colaborativos da produção.

Para Foucault a subjetividade, enquanto característica de um sujeito, é produzida pelas correlações de forças e pelas resistências que emergem das tecnologias de governamentalidade que estão em jogo a cada época, seja pelo modo como o conhecimento alcança o estatuto de ciência, seja pelas práticas de divisão e classificação das tecnologias disciplinares, seja pela associação das técnicas disciplinas com as práticas de controle, mas será sempre um modo de normalização subjetiva.

Uma das alternativas de análise da relação entre Trabalho e Educação numa abordagem biopolítica é, conforme aponta Gadelha (2009, p. 175), investigar como a norma disciplinar e a norma de regulação biopolítica desta relação se cruzam, e os lugares em que esse cruzamento se dá, no atual estrato sócio-histórico.

Um ambiente de regulamentação onde as normas disciplinares e as normas de controle se encontram no campo da educação para o trabalho é o chamado modelo de competências, o qual tem como estrato sócio-histórico de sua emergência as políticas neoliberais e o atual estágio de desenvolvimento do capitalismo. A análise desta problemática é sucintamente realizada no próximo item do presente como um elemento 
pontual para investigação das implicações da biopolítica na relação entre o trabalho e a educação.

\section{A Normalização Biopolítica da Subjetividade Produtiva na Sociedade Pós-industrial - a emergência do Sujeito Competente.}

As mudanças societárias em curso, que temos vivenciado a partir dos anos 1990, trazem novas práticas discursivas que configuram mudanças em diversas práticas de saber e poder, as quais incidem sobre variados campos sociais, mas com especial impacto nas esferas do trabalho e da educação. Numa abordagem foucaultiana, com todo o cuidado que se deve ter em utilizar tal denominação, a relação entre trabalho e educação, considerada em sua historicidade, se configura e adquire formas a partir das práticas de poder e de saber, com os efeitos de regimes de verdades que a constituem.

Tais mudanças societárias são evidenciadas por um conjunto de vocábulos e noções que se constituem numa espécie de produção discursiva aparente, sem um sentido claro. Estas novas formações discursivas, as quais operam diversos conceitos ambíguos e polissêmicos, estabelecem novas modelagens políticas da relação trabalho e educação. Tais formações discursivas podem ser exemplificadas citando-se alguns termos que compõem os discursos normativos da esfera do trabalho e da educação, tais como: flexibilidade, empregabilidade, governabilidade, empreendedorismo, competência, globalização, sociedade do conhecimento, dentre outros.

A investigação da relação entre trabalho e educação, numa abordagem biopolítica, não é uma tarefa simples e não se tem a pretensão de esgotar esta temática, mas de apenas contribuir com algumas considerações introdutórias. Parafraseando Gadelha (2009), a relação entre a biopolítica, o trabalho e a educação não constitui um fato óbvio, dado de antemão, de modo a estar devidamente apontado, analisado e dimensionado, mas sim um problema, no sentido de que não parecem suficientemente evidentes os nexos entre trabalho e educação com a tecnologia de poder biopolítico, tanto no passado como nos dias atuais.

A crítica marxista sobre a relação trabalho e educação estabelece que o trabalho, enquanto categoria fundamental da existência humana, tem a primazia sobre a educação, e os efeitos causados pelo sistema capitalista sobre aquele, materializados na apropriação da mais-valia e na divisão social do trabalho, condicionam os processos

\begin{tabular}{|l|l|l|l|l|} 
Revista Dialectus & Ano 1 & n. 1 & Julho-Dezembro 2012 & p. 240-256 \\
\hline
\end{tabular}


educativos às demandas do mercado de trabalho. Neste ambiente de interesses antagônicos de classes, a educação que é demandada pelos trabalhadores e a que é de interesse do capital, não são conciliáveis, de modo que a educação se torna um espaço social de luta que incide sobre os processos de inclusão e exclusão.

Para Antunes (2010), o sistema capitalista está em crise e esta situação incide na crise da sociedade do trabalho. Porém, para ele o trabalho ainda tem o status de centralidade, pois o trabalho abstrato cumpre papel decisivo na criação de valores de troca. A heterogeneização do trabalho e a complexificação da classe trabalhadora impõem desafios para a construção de modelos formativos dos trabalhadores que sejam capazes de enfrentar os condicionamentos do extrato sócio-histórico contemporâneo da relação entre trabalho e educação.

A perspectiva de análise proposta pela abordagem marxista é de grande relevância para a compreensão dos condicionantes sociais e políticos do modelo societário capitalista e de suas implicações para a relação entre trabalho e educação. Porém esta abordagem investigativa não tem sido suficiente para dar conta da complexificação do trabalho, da emergência de novos arranjos produtivos e do deslocamento da própria função produtiva para atividades imateriais.

Um novo estrato sócio-histórico emergiu com o crescente deslocamento do trabalho concreto para o trabalho imaterial, com mais ênfase nos anos 1990, para o qual

Cocco et al. (2003) relacionou o trabalho imaterial, e mais tudo aquilo que está vinculado à circulação e por outro lado à inovação, com um novo padrão de acumulação onde processos reprodutivos se tornam imediatamente produtivos, emancipando-se da ordem fabril do trabalho assalariado. Para o referido autor, esse deslocamento não poderia ter acontecido sem a integração crescente das novas tecnologias de informação e comunicação (NTICs) aos processos produtivos, principalmente no que diz respeito à

constituição do emaranhado de redes sociais e técnicas que sustentam e desenham territórios ou arranjos de uma cooperação produtiva não mais restrita ao chão de fábrica.

Segundo Cocco et al. (2003), a hipótese do capitalismo cognitivo sustenta-se com a perspectiva de uma transformação radical das formas de produção, acumulação e organização social abertas pelas NTICs para além das determinações neo-industriais do denominado modelo japonês ou da especialização flexível.

O novo estrato sócio-histórico do capitalismo cognitivo - onde a cognição dos trabalhadores passa a ser o mais importante fator explicativo de seus comportamentos e dos fenômenos econômicos - tem promovido o deslocamento do conceito de

\begin{tabular}{|l|l|l|l|l|} 
Revista Dialectus & Ano 1 & n. 1 & Julho-Dezembro 2012 & p. 240-256 \\
\hline
\end{tabular}


qualificação profissional para o de competência. Este deslocamento aponta para a emergência de novas formas de produção de saberes e de intervenção na relação entre trabalho e educação que evidenciam novas estratégias de normalização desta relação, em que se cruzam normas disciplinares e normas de regulação, sob a influência de novos dispositivos de controle originados pelo o avanço das novas tecnologias de informação e comunicação.

Segundo Manfredi (1999) a concepção da qualificação, no contexto da sociedade industrial, tem como matriz o modelo job/skills, definido a partir da posição a ser ocupada no processo de trabalho e previamente estabelecida nas normas organizacionais da empresa, de acordo com a lógica do modelo taylorista/fordista de organização do trabalho. Na ótica deste modelo, a qualificação é concebida como sendo adstrita ao posto de trabalho e não como um conjunto de atributos inerentes ao trabalhador.

Tal abordagem aponta para um modelo de regulação disciplinar de um trabalhador especializado e assujeitado, onde o seu corpo-máquina é treinado para desempenhar tarefas prescritas e repetitivas em seu posto de trabalho. Neste sentido a qualificação profissional é um modelo de formação orientado por uma anotomo-política que visa a produção de corpos dóceis e aptos ao desenvolvimento de tarefas produtivas individuais e fragmentadas.

A emergência dos modelos pós-fordistas de produção sob o contexto do capitalismo cognitivo tornou o modelo de qualificação profissional, para os postos de trabalho, insuficiente para atender as demandas em curso no mundo do trabalho, remetendo a uma nova abordagem social da qualificação e da organização do trabalho, a qual tem como elemento central o modelo das competências.

Um importante aspecto embutido no deslocamento do conceito de qualificação para o modelo de competência é a sua relação como um novo tipo de práticas de poder e de saber, o qual coloca a cognição e a comunicação intersubjetiva como principais fatores de desenvolvimento dos sistemas produtivos, promovendo o deslocamento da abordagem social da qualificação profissional para um novo ambiente de subjetivação e de objetivação da relação entre o objeto trabalho e o sujeito trabalhador.

Outro ponto fundamental para análise da emergência do modelo das competências, enquanto nova normalização biopolítica da qualificação e da organização do trabalho é o seu caráter "psicologizado" e sua articulação com os dispositivos das novas tecnologias de informação e comunicação. 
Por outro ângulo, o conceito de competências é tratado como uma norma de competência, a qual tem como exemplo a definição da Organização Internacional do Trabalho-OIT (1999).

As normas de competências representam um dos sistemas de normalização da sociedade pós-industrial, onde se cruzam as normas de disciplina e as normas de regulação, inseridas em um apriori histórico, que orienta o deslocamento do corpomáquina da qualificação para o corpo-informação da competência. Neste campo de visualização, as competências não representam uma negação do conceito de qualificação profissional, mas pelo contrário, constituem-se numas das principais formas de normalização da subjetividade produtiva na emergência do capitalismo cognitivo, indicando uma revalorização da qualificação, que deixa de ser um atributo vinculado a um posto de trabalho, para se tornar um atributo de um novo sujeito do trabalho.

Pelo exposto, ousa-se afirmar que a normalização das competências laborais, que se inserem tanto na esfera de organização do trabalho quanto na esfera educacional, representa uma estratégia biopolítica para a governamentalidade da relação entre trabalho e educação no estrato sócio-histórico do que vem sendo denominado de capitalismo cognitivo. Porém, os seus efeitos sobre a subjetivação e objetivação dos trabalhadores, e seu caráter de onipresença em todos os espaços sociais, associado aos dispositivos de poder das tecnologias de informação e comunicação, têm se caracterizado apenas como estratégias de elevação da produtividade e de promoção da inclusão excludente dos trabalhadores, representando novas formas de acumulação do capital.

A normalização biopolítica das competências é estruturada, segundo a OIT (1999), em unidades de competências, as quais se fragmentam em elementos de competências, critérios de desempenho, campos de aplicações e evidências de desempenho, as quais são dirigidas para o controle de competências-chaves para cada atividade produtiva. Tal organização tem grande semelhança com os dispositivos de controle das tecnologias de informação, tais como os sistemas de programação orientados a objetos e a comunicação em redes de pacotes, possibilitando tratar a competência como um pacote informacional, que tem estruturas descritivas e de orientação seqüencial, como cabeçalhos e endereços dos pacotes de dados enviados por redes de computadores. 
O modelo das competências, em sua aplicação biopolítica na relação trabalho e educação, possibilita a integração dos dispositivos disciplinares, mediante a especificação de padrões de desempenho em situações reais de trabalho e processos de auto-gestão da qualidade, com dispositivos de segurança que possibilitam a atuação preventiva sobre a população de trabalhadores flexíveis e orientados para a solução de problemas, com maior responsabilização destes sobre os processos de inovação, e com os dispositivos de controle da mente pela incorporação da empresa na subjetivação do trabalhador empreendedor e na ampliação das redes informacionais de controle, possibilitadas pelas tecnologias digitais.

Assim considerado, o modelo das competências, presente tanto na organização do trabalho, quanto na estruturação de modelos formativos flexíveis e abertos, constitui um importante componente da tessitura das novas formas de poder-saber que se cruzam nas esferas do trabalho e da educação na emergência da biopolítica enquanto estratégia de normalização de uma subjetividade produtiva flexível e inovadora, mas ainda sob o controle do capital.

\section{Considerações Finais}

A investigação da relação entre trabalho e educação, tendo como abordagem os mecanismos estratégicos agenciados pelo exercício do biopoder e da biopolítica, na ótica de Michel Foucault, possibilita operar deslocamentos que ampliam e inovam novas práticas de saber e poder que emergem das relações sociais deste campo investigativo, na conjuntura do denominado capitalismo cognitivo. Tal investigação oportuniza a identificação de novas formas de subjetivação e objetivação do trabalhador, crítico e reflexivo, em relação ao objeto do trabalho, o qual vem se tornando cada vez mais imaterial.

As implicações da governamentalidade biopolítica na relação entre trabalho e educação, enquanto categorias fundamentais da formação da subjetividade estão situadas no mesmo plano de imanência das relações de resistência aos dispositivos de exploração do capitalismo, cuja lógica produtivista se altera na era do capitalismo cognitivo, mas não se altera a sua lógica de acumulação. Neste contexto, faz-se necessário a construção de novas maneiras de viver e de trabalhar, que sejam capazes de 
criar espaços de resistência que promovam a valorização da vida qualificada (bio) em detrimento da vida desqualificada (zoe).

A educação profissional, no atual contexto, deve ser estruturada como um espaço de resistência, buscando a construção de competências ampliadas, que integrem a ciência, a tecnologia, o trabalho e a cultura, numa perspectiva de exploração de novas formas de trabalhar e de viver, por meio de processos de aprendizagens colaborativas e de trabalho em redes sociais de cooperação.

\section{Referenciais Bibliográficos}

ANTUNES, Ricardo. Adeus ao Trabalho? Ensaio sobre as metamorfoses e a centralidade do trabalho, $14^{\circ}$. Ed. - São Paulo: Cortez, 2010

BERINO, Aristóteles. O Futuro para a Teoria da Subjetividade em Marx, Dissertação de Mestrado:UFF, Niterói - RJ, 1994

COCCO, Giuseppe; GALVÃO, Alexander Patez; SILVA, Gerardo. (Orgs.). Capitalismo Cognitivo: trabalho, redes e inovação. Trad. De Eliana Aguiar. Rio de Janeiro: DP\&A, 2003.

CORRÊA, Maria Laetícia; TEIXEIRA, Alexandre Luiza. Uma Nova Faceta da Gestão Empresarial: A Conformação da Subjetividade do Trabalhador. ANPED, 2010. Disponível em WWW.anped.org.br/reunioes/23/textos/0905t.pdf

FOUCAULT Michel. Historia da Sexualidade I. A vontade saber, $2^{a}$. Edição, Rio de Janeiro: Ed. Graal, 1979.

Em defesa da sociedade. Tradução de Maria E. Galvão. São

Paulo: Martns Fontes, 2000.

O nascimento da medicina social, in: Foucault, M. Microfísica do

Poder, Rio de Janeiro: Ed. Graal, 2001 (16ª . Edição) p. 79 -98.

GADELHA, Sylvio. Biopolítica, governamentalidade e educação: introdução e conexões, a partir de Michel Foucault. Belo Horizonte: Autêntica Editora, 2009.

GADOTTI, MOACIR. Perspectivas atuais da educação. São Paulo. Perspec., jun.

2000, n. $2, \quad$ v. $14, \quad$ Disponível em: <http://www.scielo.br/scielo.php?script=sci_arttext\&pid=S0102-

$88392000000200002 \& \operatorname{lng}=$ en\&nrm=iso>. Acesso em 27 fev. 2010.

GONDIN, Eleonora Maria; RODRIGUES, Osvaldino Maria - A Ontologia e o Transcendental in: POROS, Uberlândia, v. 1, n. 2, p. 42-65, 2009 - disponível em: www.catolicaonline.com.br/poros

LIMA, Homero Luis de. Do Corpo-máquina ao corpo-informação - o pós-humano como horizonte biotecnológico, 1 ${ }^{\mathrm{a}}$. ed. Curitiba-Pr: Editora Honois Causa, Ltda,2010.

\begin{tabular}{|l|l|l|l|l|} 
Revista Dialectus & Ano 1 & n. 1 & Julho-Dezembro 2012 & p. 240-256 \\
\hline
\end{tabular}


MANFREDI, Silvia Maria. Trabalho, qualificação e competência profissional - das dimensões conceituais e políticas. Educ. Soc., Campinas, v. 19, n. 64, Sept. 1999. Disponível em <http://www.scielo.br/scielo.php?script=sci_arttext\&pid=S0101733019980003. Acessado em 03/07/2010.

MARAZZI, Cristian. O Lugar da Meias: a virada lingüística da economia e seus efeitos sobre a política, Rio de Janeiro: Civilização Brasileira, 2009.

MARX, Karl. O capital. Rio de Janeiro: Civilização Brasileira, 1968

MARX, Karl; ENGELS, Friedrich. La ideologia alemana. Montevideo: Pueblos Unidos; Barcelona: Grijalbo, 1974

OIT. Manual de procedimento metodolgico para El desarrollo e normalization de competências laborales, Institituto Nacional de Formation Tecnico Professional. Santo Domingo: CINTERFOR/OIT, 1999. Disponível em http://www.cinterfor.org.uy, acessado em 02 de julho de 2010.

SAVIANI, Demerval. Trabalho e Educação Fundamentos Ontológicos e Históricos. Revista Brasileira de Educação. São Paulo: AMPED, 2007, n. 34, v. 12, p 152 - 165.

SANSON, Cesar. Produção biopolítica é constitutiva ao capitalismo cognitivo. Liinc em Revista, V.5, n.2, setembro 2009, Rio de Janeiro, p. 2006 - 214. Disponível em http://www.ibict.br/liinc, acessado em 02 de maio de 2010.

Trabalho e Subjetividade: da sociedade industrial à sociedade pósindustrial, Tese de Doutorado, Programa de Pós-Graduação em Sociologia: UFPR, Curitiba - PR, 2009. 